
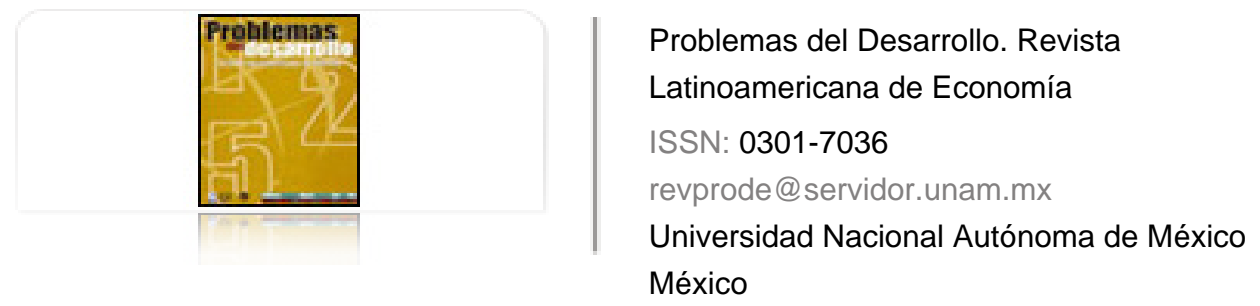

Álvarez, Lourdes; Cuadros, Liliana Las importaciones chinas y su impacto en el mercado de autopartes de repuesto mexicano Problemas del Desarrollo. Revista Latinoamericana de Economía, vol. 43, núm. 169, abril-junio, 2012, pp. $97-119$

Universidad Nacional Autónoma de México

Distrito Federal, México

Disponible en: http://www.redalyc.org/articulo.oa?id=11823064005

Cómo citar el artículo

- Número completo

- Más información del artículo

Página de la revista en redalyc.org

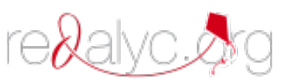

Sistema de Información Científica

Red de Revistas Científicas de América Latina, el Caribe, España y Portugal Proyecto académico sin fines de lucro, desarrollado bajo la iniciativa de acceso abierto 
Revista Problemas del Desarrollo, 169 (43), abril-junio 2012

\title{
LAS IMPORTACIONES CHINAS Y SU IMPACTO EN EL MERCADO DE AUTOPARTES DE REPUESTO MEXICANO
}

\author{
Lourdes Álvarez* y Liliana Cuadros**
}

Fecha de recepción: 24 de febrero de 2011. Fecha de aceptación: 7 de octubre de 2011.

\section{RESUMEN}

El objetivo de este trabajo es analizar cómo está siendo afectado el mercado de autopartes de repuesto en México por la introducción de autopartes chinas. El déficit de comercio entre México y China en el subsector de autopartes se ha incrementado en los últimos años y las autopartes chinas están integrándose a una estrategia de proveeduría que han implantado las empresas para bajar costos de fabricación, abrir nuevas líneas y evitar la escasez de productos. Todo esto es necesario en un mercado de repuesto que crece a tasas de $10 \%$ anual y ha tenido un aumento importante de marcas y modelos que obliga a la especialización de las empresas. Sin embargo, no existen normas sobre la calidad y desempeño de las autopartes que se introducen al país; hay problemas de piratería y se perciben en el mercado como autopartes de mala calidad.

Palabras clave: Comercio bilateral, México-China, mercado de repuesto, autopartes chinas.

\section{CHINESE IMPORTS AND THEIR IMPACT ON THE SPARE AUTO PARTS MARKET IN MEXICO}

\begin{abstract}
The aim of this paper is to examine how the spare auto parts market in Mexico is being affected by the introduction of Chinese auto parts. The trade deficit between Mexico and China in the auto parts subsector has increased in recent years and Chinese car parts belong to a supply strategy that has seen the set-up of companies to lower manufacturing costs, open new lines and avoid product shortages. This is necessary in a spare parts market growing at an annual rate of $10 \%$ where there has been an important increase in makes and models, creating a need for companies to specialize. However, quality and performance standards of the auto parts introduced to the country do not exist; there are piracy issues and the auto parts on the market are perceived as being of bad quality. Keywords: Bilateral trade, Mexico-China, spare parts market, Chinese auto parts

* Profesora titular "C" de la Facultad de Contaduría y Administración de la unam. México. Correo electrónico: malvarez@correo.fca.unam.mx

** Maestra en Administración y asesora fiscal. Correo electrónico: liliana@yahoo.com.mx
\end{abstract}


Lourdes Álvarez y Liliana Cuadros

\section{LES IMPORTATIONS CHINOISES ET LEUR IMPACT SUR LE MARCHÉ MEXICAIN DES PIÈCES DÉTACHÉES AUTOMOBILES \\ Résumé}

L'objectif de ce travail est d'analyser comment est affecté le marché des pièces détachées automobiles au Mexique par l'introduction de pièces détachées chinoises. Le déficit commercial entre le Mexique et la Chine pour ce sous-secteur de l'industrie automobile s'est accru ces dernières années, et les pièces détachées chinoises s'intègrent dans une stratégie d'approvisionnement qu'ont mise en place les entreprises pour réduire les coûts de fabrication, ouvrir de nouvelles lignes et éviter la pénurie de produits. Tout ceci est nécessaire dans un marché des pièces de rechange qui croît à un taux de $10 \%$ annuels et où a considérablement augmenté le nombre de marques et modèles, obligeant les entreprises à se spécialiser. Néanmoins, il n'existe pas de normes de qualité et performances pour les pièces détachées introduites dans le pays ; il y a des problèmes de piraterie et elles sont considérées de mauvaise qualité.

Mots clés: commerce bilatéral, Mexique-Chine, marché des pièces de rechange, pièces détachées automobiles chinoises

\section{AS IMPORTAÇÓES CHINESAS E SEU IMPACTO NO MERCADO MEXICANO DE AUTO-PARTES PARA REPOSIÇÃO \\ Resumo}

O objetivo deste trabalho é analisar como está sendo afetado o mercado de auto-partes para reposição no México pela introdução de auto-partes chinesas. O déficit comercial entre México e China no sub-setor de auto-partes aumentou nos últimos anos e as auto-partes chinesas estão integrando-se à estratégia de subministro que as empresas implantaram para baixar os custos de fabricação, abrir novas linhas e evitar escassez de produtos. Tudo isso é necessário num mercado de reposição que cresce a taxas de 10\% ao ano e teve um aumento importante de marcas e modelos que obriga à especializaçáo das empresas. Contudo, no existem normas sobre qualidade e desempenho das autopartes que se introduzem no país, há problemas de pirataria e se percebem no mercado como auto-partes de má qualidade.

Palavras-chave: Comércio bilateral; México-China; Mercado de reposição; Auto-partes chinesas.

中国汽车零配件进口及其对, 墨西哥的冲击。

摘要：本文的目标是分析进口中国汽车零配件是如何影响墨西哥市场的。近 年来, 墨中两国的汽车零配件贸易赤字不断扩大。中国的汽车零配件生产企 业已实施了供应战略, 即低成本生产、开设新的生产线和避免产品短缺。墨 西哥汽车零配件市场年增长 $10 \%$, 且不断有重要的品牌和款型出现, 这就 迫使汽车零配件生产企业更加专业化。然而, 从中国进口的产品缺乏质量和 执行标准, 且存在侵权问题, 也被认为质量低劣。

关键词: 双边贸易, 墨西哥一中国, 汽车零配件市场, 中国汽车零配件 
Las importaciones chinas y su impacto en el mercado de autopartes de repuesto mexicano

\section{INTRODUCCIÓN}

En los últimos veinte años la República Popular China ha logrado un desarrollo acelerado de su industria automotriz y de autopartes. Actualmente tiene capacidades para fabricar todo tipo de vehículos y su volumen de producción pasó de 222 mil a 18.3 millones de unidades entre 1981 y 2010 (Fourin, 2005; OICA, 2010). La tasa de crecimiento que presenta no tiene precedentes, ni siquiera al compararla con el crecimiento observado en Estados Unidos en 1950 o con Europa o Japón en 1960 (Freyssenet, 2009).

Inicialmente la producción automotriz en China era para el consumo interno pero las exportaciones de autopartes chinas han ido aumentando desde 1990, especialmente los productos de alta tecnología (Jenkins y Dussel, 2006). Esto se relaciona con sus planes de gobierno y su política industrial que han apoyado el crecimiento de la producción y las exportaciones automotrices como medio para incentivar el crecimiento de la economía (Álvarez y Sepúlveda, 2006; Álvarez, 2007; Dussel, 2010a; 2010b).

En el último lustro se ha visto un aumento en la introducción y comercialización de autopartes chinas al mercado de autopartes de repuesto mexicano, por lo que nos interesa conocer: la dinámica de sus importaciones, cómo se comporta el subsector que surte al mercado de repuestos ante estos eventos y el grado de aceptación que tienen los productos en el mercado mexicano.

El mercado de autopartes de repuestos mexicano y el subsector que lo surte han sido poco estudiados. En este trabajo se llevó a cabo una investigación documental y otra de campo: en primer lugar se realizó una revisión sobre estudios de comercio bilateral entre México y China dando especial atención al análisis de las importaciones de autopartes y utilizando la base de datos cometrade map. ${ }^{1}$ El trabajo de campo se inició con entrevistas estructuradas para comprender la problemática del sector. Cinco expertos fueron entrevistados en dos ocasiones; la primera vez en 2009 durante la crisis económica y la segunda al principio de 2011 después de un periodo de recuperación del sector. A partir de la información obtenida se formuló un cuestionario que fue aplicado en cada ocasión a una muestra aleatoria de 56 empresas seleccionadas del directorio de la Asociación de Representantes de Importadores y Distribuidores de Refacciones Automotrices (ARIDRA) para saber si vendían partes automotrices chinas y su opinión sobre las mismas.

El artículo se estructuró en tres partes. En la primera se analiza el comercio de autopartes México-China dándole especial atención a las importaciones mexicanas y a la situación del sector de autopartes en China donde se hace evidente la

1 comtrade map, http://www.trademap.org/Product_SelProduct_TS.aspx 
Lourdes Álvarez y Liliana Cuadros

intención del gobierno de seguir impulsando el crecimiento de las exportaciones automotrices y de autopartes. En la segunda parte se describe la estructura y las características del mercado de repuestos en México, se contrasta la opinión que tenían los expertos en 2009 y posteriormente en 2011 sobre la problemática del mercado y sobre el impacto de las autopartes chinas y se analizan los resultados de las encuestas hechas a las refaccionarias. Finalmente se presentan las conclusiones.

\section{EL COMERCIO ENTRE MÉXICO Y CHINA}

El comercio entre México y China ha crecido rápidamente y en la actualidad China se posiciona como nuestro segundo socio comercial después de Estados Unidos. El comercio bilateral con Estados Unidos se ha triplicado entre 1995 y 2010 pasando de 119,018 a 383,364 millones de dólares mientras que con China aumentó 67 veces pasando de 736 a 49,805 millones de dólares. Sin embargo en 2010 el comercio con Estados Unidos representó 63.93\% mientras que con China fue de tan sólo 8.1\%, lo que muestra la gran dependencia comercial que aún tenemos con Estados Unidos y que a pesar del gran crecimiento del comercio con China, aún debemos diversificar más nuestros socios comerciales (Cuadro 1).

Esta visión cambia cuando analizamos la balanza comercial con Estados Unidos que es superavitaria mientras que con China el déficit comercial pasó de 304 a 41,409 millones de dólares. Las grandes asimetrías en el comercio de México con China se explican principalmente por la compra de bienes intermedios de los sectores de electrónica, eléctrico e informática que se utilizan en la producción de vehículos y televisiones que posteriormente se exportan a Estados Unidos. Este rubro representó 47.7\% de las importaciones en 2010 (Secretaría de Economía, 2011).

Destaca que la participación de las importaciones que hacemos de Estados Unidos llegó a ser de $74.29 \%$ en 1995 y se redujo a $48.10 \%$ en 2010 mientras que China incrementó su participación pasando de 0.72 a $15.13 \%$ en el mismo periodo.

Es de esperarse que la tendencia arriba descrita se mantenga ya que en diciembre de 2011 terminará el Acuerdo en Materia de Medidas de Remedio Comercial y las medidas que aún protegen a algunas industrias se eliminarán permitiendo el incremento de las importaciones provenientes de China. Es por esto que idear mecanismos que ayuden a regular el comercio e implementar acciones para contrarrestar el creciente déficit de la balanza comercial se ha vuelto de primordial importancia.

Para contrarrestar el déficit y enfrentar la terminación del acuerdo arriba señalado, varios autores coinciden en proponer que los países busquen 
complementarse. Si China incrementa su inversión extranjera (IE) en México y cumple con las reglas de origen, puede aprovechar el acceso preferencial a Estados Unidos beneficiándose de la desgravación arancelaria (Martínez, 2010; Morales, 2010; Dussel, 2010a y 2010b). Por ejemplo, en 2009 México tenía un arancel promedio de $0.10 \%$ para exportar productos al mercado de Estados Unidos mientras que China lo tenía de 3.64\%; esto representa tener que pagar 36.4 veces más de arancel (Dussel, 2010b).

Martínez (2010) también propone acuerdos de asociación económica que eliminen obstáculos y aumenten la cooperación en el comercio de los capítulos de la Tarifa de la Ley de Impuestos Generales de Importación y Exportación (TIGIE) que tengan mayor intercambio, promoviendo así nuevos mecanismos comerciales de acceso preferencial, evitando prácticas desleales y contrabando, y

Cuadro 1. México: Balanza comercial con sus dos principales socios ${ }^{2}$

Millones de dólares

\begin{tabular}{lccccccc}
\hline & 1995 & 2000 & 2005 & 2007 & 2008 & 2009 & 2010 \\
\hline $\begin{array}{l}\text { Exportaciones } \\
\text { a EUA }\end{array}$ & $65,190.00$ & $146,214.50$ & $183,562.80$ & $223,403.60$ & $234,557.10$ & $184,878.50$ & $238,357.50$ \\
$\begin{array}{l}\text { Importaciones } \\
\text { de EUA }\end{array}$ & $53,828.50$ & $127,534.40$ & $118,547.30$ & 140,569 & $152,615.20$ & $112,433.80$ & $145,007.40$ \\
Saldo & $11,361.50$ & $18,680.10$ & $65,015.50$ & $82,834.60$ & $81,941.90$ & $72,444.70$ & $93,350.10$ \\
& & & & & & & \\
$\begin{array}{l}\text { Exportaciones } \\
\text { a China }\end{array}$ & 215.80 & 310.40 & $1,135.60$ & $1,895.90$ & $2,046.90$ & $2,215.60$ & $4,197.80$ \\
$\begin{array}{l}\text { Importaciones } \\
\text { de China }\end{array}$ & 520.60 & $2,879.50$ & $17,696.30$ & $29,791.90$ & $34,754.50$ & $32,529.00$ & $45,607.60$ \\
Saldo & -304.80 & $-2,569.10$ & $-16,560.70$ & $-27,896.00$ & $-32,707.60$ & $-30,313.40$ & $-41,409.80$ \\
\hline
\end{tabular}

Fuente: Secretaría de Economía, Estadísticas de comercio internacional, http//www. Economía.gob, México 19 de septiembre de 2011.

2 De acuerdo con Morales (2010), cuando China fue aceptada en la Organización Mundial de Comercio adquirió la obligación de negociar con México la prolongación de la vigencia de cuotas compensatorias en la industria del calzado y la cadena textil y confección por seis años. Terminado este tiempo, en 2008, se negoció el Acuerdo en Materia de Medidas de Remedio Comercial aplicándose medidas de transición temporal que se eliminarían progresivamente hasta que en diciembre de 2011 queden totalmente eliminadas. 
Lourdes Álvarez y Liliana Cuadros

creando figuras para solucionar disputas antes de llegar a confrontaciones que los obliguen a usar los mecanismos de solución de controversias.

Por otro lado, la triangulación y las importaciones ilegales de bienes chinos son problemas para las empresas productoras. La triangulación genera grandes discrepancias entre las estadísticas de exportación de un país y las estadísticas recíprocas de importación. Esto ocurre porque "las exportaciones casi siempre se registran en el país de destino sin poder determinarse si más adelante los bienes serán revendidos y reexportados a uno o varios países. En sentido contrario las importaciones se registran según el país de origen del producto sin considerar el país de procedencia y puede ser que no sea el mismo" (Morales, 2008).

Cuando los productos chinos entran a los Estados Unidos como importaciones temporales y son reexportados a México con la etiqueta "hecho en Estados Unidos" México enfrenta una triangulación (Dussel, 2005; Morales, 2008 y 2010). La triangulación masiva de bienes chinos se ha dado a través de los puertos de Estados Unidos especialmente el de Long Beach (Dussel, 2010b). Esto beneficia a algunas empresas extranjeras intermediarias pero va en detrimento de una relación entre empresas chinas y mexicanas. Por ejemplo, en 2007 se reexportaron de Estados Unidos a México 942.7 millones de dólares del capítulo 87 del sistema armonizado "vehículos automóviles, tractores, ciclos y demás vehículos terrestres; sus partes y accesorios" que representó $0.07 \%$ de las importaciones del capítulo que hizo México en ese año (Morales, 2008).

México y China han dado poca importancia a la identificación y promoción de oportunidades de mercado y han puesto su atención en buscar medidas para combatir prácticas desleales de comercio, uso de subsidios y contrabando de mercancías chinas (Villalobos, 2007). Sin embargo, en los tres últimos años los aranceles han disminuido: 91.7\% de las importaciones entran al país sin pagar arancel, 58\% de las fracciones arancelarias tenían tasa cero en 2010 y aquellas que tenían que pagar impuestos tenían como arancel promedio 5.3\%, Martínez (2010) y se espera que esto coadyuve a disminuir el contrabando y algunas prácticas desleales de comercio.

En efecto, la apertura comercial sigue disminuyendo barreras arancelarias, pero la situación no es igual para todos los productos ni todos los países. Dussel (2010b) estudió cinco subpartidas de la cadena autopartes automotriz, encontrando que no existe arancel de importación para los países con los que México cuenta con un tratado de libre comercio. En cambio China, que no recibe trato arancelario preferencial, pagaba un arancel del $5 \%$ en diez subpartidas de autopartes y el arancel para autos nuevos (vehículos para transporte de personas de cilindrada entre 1500 o $3000 \mathrm{~cm}^{3}$ ) era de 30 a $50 \%$. Este arancel para autos nuevos y para países con los que México no tiene acuerdo comercial disminuirá a partir del primero de enero de 2012 a 20\%. 


\section{La industria automotriz en México y las importaciones chinas}

La industria automotriz en México se convirtió en una plataforma exportadora a partir de la firma del Tratado de Libre Comercio de América del Norte a partir del cual logró una tasa de crecimiento de 91.6\% entre 1994 y 2008 pasando de 1 a 2.1 millones de unidades producidas. En 2009, la producción de automóviles cayó $28 \%$ y el sector de autopartes perdió $29 \%$ de la producción pasando de 53,100 a 41,227 millones de dólares (INA, 2009). El siguiente año se tuvo una recuperación importante y la producción de automóviles creció $52 \%$ respecto a 2009 y $14.4 \%$ respecto a 2008 alcanzando 2.2 millones de vehículos que ha sido su punto más alto de producción (AMIA, 2010; 2011). De la misma forma el sector de autopartes incrementó su producción a 60 mil millones de dólares (45.55\%) con respecto a 2009 (INA, 2008, 2009 y Ríos, 2011).

Ante este panorama Estados Unidos se ha mantenido como nuestro principal socio comercial en la cadena de autopartes automotriz (CAA) ${ }^{3}$ pero ha ido disminuyendo su participación en el total de las importaciones que hace México de 75 a $49 \%$ entre 1995 y 2009. China por su parte se convirtió en el segundo socio comercial desde 2008 participando con $9.68 \%$ de las importaciones y creció a $11.94 \%$ en 2009 . Por otro lado, $82 \%$ de las exportaciones que hace México de la CAa se envían a Estados Unidos y únicamente $0.40 \%$ a China. Aun así éstas tuvieron una tasa de crecimiento de 54\% entre 1995 y 2009 pasando de 20 a 140 millones de dólares (Dussel, 2010b).

Entre las principales autopartes que México importa de China se encuentran partes mecánicas para vehículos, neumáticos, acumuladores eléctricos, asientos, dispositivos de arranque, árboles de transmisión y rodamientos. ${ }^{4} \mathrm{Si}$ analizamos el capítulo 87 de la tarifa arancelaria del sistema armonizado "Vehículos automóviles, tractores, velocípedos y demás vehículos terrestres; sus partes y accesorios" observamos que las exportaciones que hace México a China crecieron a una tpp de $53.73 \%$ mientras que las importaciones crecieron a una menor tasa (26.55\%). Sin embargo la balanza comercial de este capítulo presenta un saldo negativo en la última década. Las exportaciones mexicanas aumentaron gracias al crecimiento de la producción de vehículos en China y se triplican entre

3 La cadena autopartes automotriz es un conjunto de subpartidas seleccionadas por el autor del total de capítulos de la tarifa arancelaria. En este análisis se incluyen de forma agregada 129 subpartidas: 112 de autopartes y 17 de automotriz.

4 comtrade map, http://www.trademap.org/Product_SelProduct_TS.aspx consultado el 19 de septiembre 2011. Incluyen partes de motocicleta 
Lourdes Álvarez y Liliana Cuadros

2009 y 2010 mientras que las importaciones cayeron en 2009 debido al impacto de la crisis económica y a la disminución de la producción de automóviles en México, pero se recuperaron en 2010 (Cuadro 2). De hecho, 15\% de las importaciones que hace México del capítulo 87 vienen de China mientras que únicamente $0.30 \%$ de las importaciones que hace China de este capítulo son mexicanas (Come Trade map., 2011).

En la última década las importaciones de autopartes procedentes de China fueron 2.6 veces más que las exportaciones, en cambio, las importaciones de autopartes que hace China de México; no representan ni siquiera el 1\% de su total, lo que nos dejaría ver que hay oportunidades perdidas en este renglón. Sin embargo, hay que recordar que una tercera parte del sector fabricante de autopartes está formado por multinacionales y su producción queda en unos portafolios de productos que se complementan más que competir aunque en ocasiones esto sí suceda. Estas empresas privilegian el comercio intrafirma y las exportaciones a China no siempre son necesarias ya que las empresas producen en ese país.

Cuando desagregamos el capítulo 87 a diez dígitos encontramos que $84.39 \%$ de las importaciones son de autopartes y la importación de vehículos completos

Cuadro 2 . Balanza comercial automotriz México/China

Capítulo 87 de la tarifa arancelaria del sistema armonizado "Vehículos automóviles, tractores, velocípedos y demás vehículos terrestres; sus partes y accesorios"

Miles de dólares

\begin{tabular}{ccccc}
\hline Año & Exportaciones & Importaciones & Saldo & $\begin{array}{c}\text { Crecimiento del déficit } \\
\text { anual \% }\end{array}$ \\
\hline 2001 & 8,686 & 78,138 & $-69,452$ & 0.0 \\
2002 & 22,154 & 103,302 & $-81,148$ & 16.84 \\
2003 & 49,337 & 138,991 & $-89,654$ & 10.48 \\
2004 & 14,294 & 238,608 & $-224,314$ & 150.19 \\
2005 & 51,507 & 335,685 & $-284,178$ & 26.68 \\
2006 & 199,437 & 488,096 & $-288,659$ & 1.57 \\
2007 & 211,988 & 653,659 & $-441,671$ & 53 \\
2008 & 180,836 & 785,530 & $-604,694$ & 36.91 \\
2009 & 208,637 & 537,476 & $-328,839$ & -45.61 \\
2010 & 640,480 & 823,697 & $-183,217$ & -44.28 \\
tpp & 53.73 & 26.55 & & \\
\hline
\end{tabular}

Fuente: comtrade map, http://www.trademap.org/Product_SelProduct_TS.aspx consultado el 19 de septiembre 2011. Incluyen partes de motocicleta. 
es mínima. Entre las autopartes que más peso relativo tienen encontramos: accesorios, radiadores, frenos, frenos de disco, transmisiones, ejes, cajas de cambio, embragues, rines y llantas, volantes y columnas, y cajas de dirección. Las partes mecánicas tienen las mayores tasas de crecimiento y se observa un incremento para autopartes de vehículos para el transporte de personas de cilindrada superior a $1000 \mathrm{~cm}^{3}$ y superior a $1500 \mathrm{~cm}^{3}$ que están registrados en la partida arancelaria 8703. Los vehículos registrados en esta partida fueron importados con anterioridad, lo que indica que se importan sus partes de repuesto.

\section{La situación del subsector de autopartes en China}

China ha realizado un esfuerzo impresionante en las últimas décadas para lograr el escalamiento de la cadena autopartes automotriz y aunque sus niveles de ciencia y tecnología no se equiparan con aquellos de los países industrializados, sus marcas propias ya se comercializan en varias partes del mundo y sus exportaciones de autopartes son crecientes (Dussel, 2010b).

La industria automotriz china se desarrolló a partir de las reformas económicas de la década de los ochenta que buscaban transformar una industria automotriz fragmentada, sin recursos financieros y con tecnologías obsoletas en un oligopolio en el que dominaran grupos automotrices chinos y la inversión extranjera participara con recursos financieros, tecnológicos y conocimientos administrativos. La armonización en el cambio de políticas de inversión extranjera, comerciales, de consumo y del sector automotriz, lograron un crecimiento extraordinario de la producción y un cambio en la estructura de la industria (Álvarez y Sepúlveda, 2006; Álvarez, 2007; Dussel, 2010a, 2010b).

La Política Industrial del Sector Automotor (PISA) promulgada en julio de 1994 impulsó el crecimiento de la industria al promover la inversión extranjera y estableció prioridades para desarrollar componentes y partes automotrices, autobuses de pasajeros, camiones, motocicletas para la industria doméstica. Posteriormente, en el Décimo Plan Quinquenal (2001-2005) la visión del desarrollo de la industria buscaba establecer dos o tres grupos automotrices internacionales y competitivos y la formación de tres grupos de productores de autopartes que surtieran $70 \%$ del mercado doméstico, mientras que las exportaciones de autopartes deberían representar $20 \%$ del total de las ventas. ${ }^{5}$

5 El texto completo en inglés: http://english.peopledaily.com.cn/features/lianghui/zhureport. html 
Lourdes Álvarez y Liliana Cuadros

La PISA publicada en 2004 cambió la visión de desarrollo de la industria y tuvo como actor principal al consumidor de vehículos particulares, por lo que incluyó reglas para su protección y la del ambiente. En ésta se previó y estimuló el crédito para el consumo de vehículos y servicios como seguros, talleres automotrices y estacionamientos. Se puso especial atención a la industria de autopartes esperando que los fabricantes se insertaran en las cadenas productivas mundiales y se prepararon programas y recursos para que los fabricantes más fuertes desarrollaran su habilidad para comprometerse en la producción en masa y ser proveedores de módulos para la industria terminal. Para mantener el crecimiento de la industria automotriz se desarrollaron las industrias: metalúrgica, petroquímica, maquinaria, electrónica y textil.

Durante la crisis de 2009 los resultados que obtuvieron los fabricantes de automóviles ubicados en China fueron excepcionales ya que incrementaron $21 \%$ sus ingresos y $52 \%$ sus utilidades. Lograron estos resultados gracias a que mantuvieron relativamente estable el precio de las materias primas, una tasa de utilización de la capacidad instalada alta y un rápido crecimiento de la producción del mercado automotriz de China (Research Departament of Industrial Economy, 2010).

En cuanto a las exportaciones, entre 2001 y 2008, el sector de autopartes presentó un crecimiento acelerado pasando de 1,632 a 27,195 millones de dólares. A partir de 2005 la balanza de autopartes se volvió superavitaria, lo que se relaciona con la implantación de la Política Industrial del Sector Automotriz

Cuadro 3. China balanza comercial de autopartes 2001-2009

Millones de dólares

\begin{tabular}{cccc}
\hline Año & Valor exportaciones & Valor importaciones & Diferencia \\
\hline 2001 & 1,632 & 2,618 & -986 \\
2002 & 1,661 & 2,312 & -651 \\
2003 & 5,420 & 7,384 & $-1,964$ \\
2004 & 7,946 & 8,679 & -733 \\
2005 & 9,889 & 7,685 & 2,204 \\
2006 & 19,248 & 10,525 & 8,723 \\
2007 & 28,691 & 12,009 & 16,682 \\
2008 & 27,195 & 12,681 & 14,514 \\
2009 & 15,116 & 14,605 & 511 \\
\hline
\end{tabular}

Fuente: Research Departament of Industrial Economy, 2010, pp. 238. 
(PISA) de 2004 y con la estrategia de las multinacionales de autopartes de trasladar procesos productivos a China buscando mano de obra barata (Álvarez, 2007). Entre 2008 y 2009 las exportaciones de autopartes chinas fueron afectadas por la crisis económica financiera y la tendencia de proteccionismo que se desarrolló en los diferentes países, por lo que las exportaciones de autopartes cayeron 44.4\% (Research Departament of Industrial Economy, 2010).

El desarrollo económico y social de China ha provocado el incremento del precio de la mano de obra y la pérdida de ventajas comparativas. Sin embargo el gobierno chino decidió incentivar las exportaciones de autopartes por el arrastre que tiene con las industrias complementarias y por ser una industria intensiva en capital y tecnología. Dentro de sus planes está construir una base de exportación caracterizada por innovación independiente, el orden y la regulación en exportaciones y la protección de derechos de propiedad. Actualmente, China busca la internacionalización de sus empresas para que éstas se ubiquen cerca de los mercados que surten y para que adquieran nuevas tecnologías. Entre sus estrategias se marca el desarrollo de una importante base tecnológica para la electrónica automotriz que sirva como un elemento clave en el desarrollo y reestructuración de toda su industria (Research Departament of Industrial Economy, 2010). La intención de China de establecer un estándar en electrónica como barrera de entrada al mercado y a la cadena de valor preocupa a los fabricantes mundiales de automóviles, por lo que han desarrollado estrategias de cooperación en investigación y desarrollo que les aseguren la pertenencia a la cadena de valor y la entrada a los mercados.

Otro factor que impulsó el crecimiento y exportaciones de autopartes chinas es que las empresas multinacionales han elegido países como China para fabricar autopartes de baja tecnología o intensivas en mano de obra. Para responder a esta oportunidad, China planeó levantar gradualmente el sistema de control del sector de autopartes y aprovechar oportunidades para fusionarse, reorganizarse, expandirse y escalar sus productos (Research Departament of Industrial Economy, 2010).

Por otro lado, en 2009 en el mundo muchas empresas de autopartes quebraron, ello creó una situación favorable para que las empresas chinas desarrollaran estrategias de crecimiento, comprando empresas que les darían acceso a tecnología de punta y mercados en países desarrollados. Por ejemplo, Beijing West Industries adquirió Delphi Absorber and Break Businesses, lo que le dio acceso a tecnología avanzada y a la cadena de abastecimiento de Delphi, que es una de las empresas productoras de autopartes más grandes del mundo. Todo esto sugiere que China se está convirtiendo en el proveedor de autopartes más importante del mundo. 
Lourdes Álvarez y Liliana Cuadros

\section{EL MERCADO DE AUTOPARTES DE REPUESTO EN MÉXICO}

El sector de autopartes surte tres mercados: el de empresas ensambladoras, conocido como terminal, el de exportación y el mercado de repuesto. A pesar de la difícil situación que cruzó el sector y que la demanda interna de vehículos nuevos no se ha recuperado ya que creció $8 \%$ en comparación con 2009, pero se mantuvo 20\% por debajo del nivel que tenía en 2008 (AMIA, 2011) el mercado de repuesto ha tenido un crecimiento sostenido con incremento en las ventas de $10.88 \%$ entre 2009 y 2010 y se espera un crecimiento de $13.7 \%$ en 2011 (Calderón, 2011). Este fenómeno se relaciona con tres factores: crecimiento y antigüedad de la flota vehicular y situación económica de los consumidores.

La flota vehicular creció $42.85 \%$ entre 2006 y 2010 pasando de 21 a 30 millones de unidades; la mayoría (66.4\%) son vehículos de pasajeros, $28.6 \%$ son camiones y camionetas para carga y tan sólo $1 \%$ camiones de pasajeros. El parque vehicular tiene una edad promedio de 16 años (INEGI, 2010); sin embargo existen registrados de forma agregada 8.9 millones de vehículos modelo 1985 y anteriores, de los cuales se desconoce la estructura de antigüedad y estas unidades tendrían por lo menos 26 años. Debido a que la recuperación económica del país es lejana, el consumo interno no se recuperará en el corto plazo y no se podrá renovar el parque vehicular, lo que fuerza una reparación constante con un gasto promedio de 250 dólares por unidad (Calderón, 2011). Actualmente se considera que el mercado de repuesto tiene un valor aproximado de 124,179 millones de pesos incluyendo vehículos, autobuses y camiones (INEGI, 2010).

En el Cuadro 4 se presenta una proyección del valor de mercado de autopartes de repuesto para vehículos ligeros en diferentes ańos. Se espera que el gasto en llantas y en sistemas electrónicos aumente a una tpp 7.68 y $6.89 \%$ entre 1999 y 2019 , que es la más alta entre los factores estudiados. El gasto en reparaciones mecánicas disminuirá su participación en 12 puntos porcentuales, mientras que el gasto en sistemas electrónicos aumentará 4 puntos, ya que los automóviles tienen cada vez más componentes electrónicos.

El mercado de repuesto está fragmentado y formalmente lo constituyen los fabricantes de autopartes, los distribuidores mayoristas, rectificadores y reconstructores de autopartes, las refaccionarias que venden partes nuevas y usadas, las tiendas de autoservicios, las agencias distribuidoras de vehículos automotrices, las empresas que venden autopartes usadas o "deshuesaderos", los talleres y los consumidores en su estructura formal (Figura 1).

Dentro de la estructura formal encontramos 1,236 fabricantes que manufacturan principalmente motores de gasolina y sus partes, equipo eléctrico y electrónico y sus partes, sistemas de dirección y de suspensión, sistemas de frenos, sistemas 
Las importaciones chinas y su impacto en el mercado de autopartes de repuesto mexicano

Cuadro 4. Cálculo del valor del mercado de autopartes de repuesto de vehículos ligeros en México Millones de dólares

\begin{tabular}{lrrrrr}
\hline & 1999 & 2004 & 2009 & 2014 & 2019 \\
\hline Gastos en mecánica & 1621 & 1910 & 2250 & 2680 & 3240 \\
Gastos en llantas & 480 & 740 & 1240 & 1550 & 2110 \\
Ventanas, cristales y otros & 147 & 176 & 210 & 270 & 330 \\
Gasto en sistema eléctrico & 512 & 616 & 800 & 970 & 1180 \\
Gasto en sistemas electrónicos & 261 & 359 & 470 & 680 & 990 \\
Total del mercado de repuesto & 3021 & 3801 & 4970 & 6150 & 7850 \\
\hline
\end{tabular}

Fuente: Reunión de evaluación del mercado de repuesto, INA con datos de The Freedonia Group, dic., 2010.

de transmisión, asientos y accesorios de interiores, y piezas metálicas troqueladas. En esta categoría encontramos empresas multinacionales como Bosch, Delphi, Hella, Gates de México, etcétera que fabrican y/o importan autopartes o componentes de otros países en donde se encuentran otras filiales del grupo. Las autopartes de estas empresas, importadas o hechas en México, se identifican en el mercado como "refacciones de marca" y su calidad es reconocida. Las autopartes fluyen hacia los mayoristas, el comercio al menudeo que incluye cadenas de refaccionarias que pueden comprar grandes volúmenes, y hacia concesionarias que venden autopartes y además tienen servicios de reparación de automóviles.

El comercio al por mayor reporta 994 unidades económicas que venden autopartes nacionales e importadas que compran a los fabricantes o importan directamente. Sin embargo existe un grupo de mayoristas independientes que son grandes distribuidores que ejercen un control importante sobre el mercado y dan servicios especializados a sus clientes sobre manejo de inventarios. También tienen cadenas de tiendas que venden al por menor.

El comercio al por menor reporta 29,019 unidades dedicadas a la venta de partes y refacciones nuevas para automóviles, camionetas y camiones y 4,685 unidades dedicadas a la venta de autopartes usadas. Una forma reciente de comercio al por menor de autopartes se da con las tiendas de autoservicio $(3,319)$ que distribuyen baterías, llantas y rines entre otros. Este sistema no siempre es conveniente ya que el sistema de depósito reembolso de las baterías fue trastocado al permitirse su venta en los supermercados.

Existen 6,492 unidades dedicadas a la venta de autos nuevos y usados de las cuales 1,600 son agencias concesionarias de los fabricantes de automóviles establecidas en 210 ciudades y distribuyen 42 marcas de automóviles, camiones y sus partes. 
Lourdes Álvarez y Liliana Cuadros

Finalmente se encuentran reportados 322,784 talleres automotrices que dan servicio de reparación a 30.7 millones de vehículos. Los talleres son una fuente importante de ventas y los mecánicos influyen la decisión de compra porque asesoran al consumidor final respecto a marcas, calidad y precios.

En este mercado inciden también las compañías de seguros nacionales y extranjeras, especialmente de los Estados Unidos, ${ }^{6}$ que venden vehículos que han sido declarados pérdida total. Las autopartes susceptibles de usarse fluyen al mercado de repuesto y son partes originales a precios económicos.

Como el sector está fragmentado, ninguna empresa tiene una gran participación en el mercado ni puede influir profundamente en los resultados de todas las demás. Tiene ausencia de líderes con suficiente poder para regular los acontecimientos, barreras débiles contra la entrada de nuevos jugadores, altos costos de inventarios y fluctuaciones imprevisibles de las ventas (Porter, 1990).

Las pequeñas empresas de este sector tienen baja capacidad financiera, escasos conocimientos de administración, limitaciones para el uso de tecnologías informáticas, y su principal factor de éxito es el manejo de inventarios. Sin embargo, los pedidos por Internet, catálogos electrónicos, el telemarketing y el uso de dispositivos móviles como Scan Telcel, son herramientas cada vez más usadas por los distribuidores y adoptados por las empresas (Calderón, 2011).

La guerra de precios en el sector los lleva a la reducción de márgenes de ganancia, y la insuficiente producción de autopartes lleva a aumentar las importaciones y a tener nuevas líneas de producto. Esto crea oportunidades al ampliar el portafolio de productos y ayuda a reducir los costos. Las importaciones de China se han incrementado dramáticamente hasta $40 \%$ de las ventas en algunas empresas ${ }^{7}$ (Reunión del Mercado de Repuestos, REMER, 2011).

\section{Consulta a expertos sobre la problemática del mercado de repuesto}

Debido a que la información sobre el mercado de repuesto es escasa, se comenzó por realizar entrevistas a profundidad con cinco expertos en dos ocasiones. La primera fue durante 2009 (Cuadros, 2009) y la segunda en enero de 2011. Se trataron tres temas básicos: nuevas tendencias en el mercado de repuesto, principales problemas del mismo y la manera en que compiten las autopartes chinas.

6 Entrevista realizada con el líder de los vendedores de autopartes usadas, "yonkeros", de Ciudad Juárez, Chihuahua en 2006.

7 Información obtenida en la encuesta abierta de la Reunión de Evaluación del Mercado de Repuesto organizada por la Industria Nacional de Autopartes en enero de 2011. 
Figura 1. Estructura del mercado de autopartes de repuesto en México

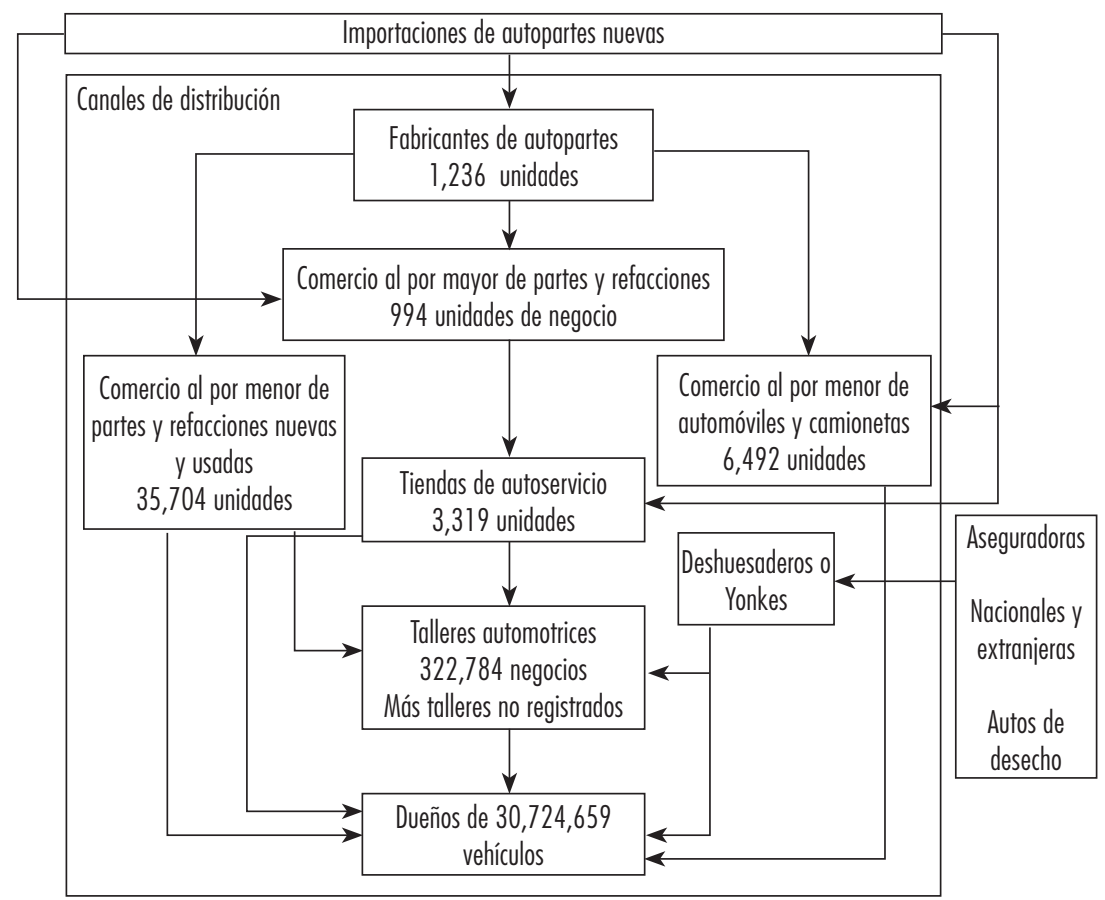

Fuente: elaborado con datos de Calderón y Censo Económico de 2009, INEGI, 2010.

\section{a) Nuevas tendencias en el mercado de repuesto}

En 2009 los expertos consideraron la especialización como la tendencia más importante; la incorporación de nuevas marcas automotrices estaban obligando a las refaccionarias a especializarse por marca y por modelo, ya que no podían tener altos inventarios. En 2011 los expertos consideraron que la introducción de productos chinos, taiwaneses y brasileños era la principal tendencia. Ésta va en aumento y la visión de los empresarios mexicanos ha cambiado de considerar estos productos como una amenaza a integrarlos a su producción para bajar costos, o a su catálogo para ampliar líneas y ofrecer mejores precios.

\section{b) Principales problemas}

Tanto en 2009 como en 2011 la falta de regulación se percibió como uno de los principales problemas. En México no existen normas sobre la calidad y 
Lourdes Álvarez y Liliana Cuadros

desempeño de las autopartes que se introducen al país. En repetidas ocasiones se ha solicitado al gobierno mexicano que actúe y exija un estándar de calidad en beneficio del consumidor, sin embargo no se han desarrollado normas específicas.

La piratería también fue mencionada en ambas ocasiones y es un problema principalmente para los fabricantes. Las empresas chinas y taiwanesas que participan en las exposiciones tienden a copiar autopartes de las otras empresas y no se toman acciones concretas al respecto. Las agrupaciones de fabricantes de autopartes responden a este problema organizando foros para que los distribuidores aprendan a identificar autopartes originales de productos piratas; sin embargo el gobierno no se enfoca en resolver este problema.

La triangulación fue mencionada como un problema importante hace dos años, pero en 2011 le dieron menos importancia. Esto se debe a que muchos productos no pagan arancel o éstos han bajado, por lo que las empresas están haciendo más importaciones legales. Además, son las multinacionales las que más importan productos, especialmente componentes, y lo pueden manejar como comercio intrafirma.

Otro de los problemas que aún se tienen es la inseguridad en las carreteras que afecta el mercado de repuesto de dos formas: aumenta el costo de operación por los seguros y sistemas de seguridad que se utilizan, y la mercancía robada se vende a precios muy bajos que afectan el mercado.

\section{c) Manera en que se comportan las autopartes chinas}

La percepción de la competencia de autopartes chinas en el mercado de repuesto ha cambiado. En 2009 se consideraba que no habían logrado penetrar en forma importante por lo que no eran una amenaza en México. Sin embargo ahora se considera que las autopartes chinas tienen una amplia penetración pero se las considera como una oportunidad para bajar los costos de fabricación, introducir nuevas marcas y líneas con precios más bajos. Debido a que el mercado tiene problemas de desabasto de autopartes, las importaciones ayudan a solucionarlo. Consideran que las autopartes chinas son convenientes a pesar de que hay que pagar por adelantado incluyendo impuestos, y esperar hasta 45 días para que se surta el pedido.

\section{Resultados de la encuesta a refaccionarias}

La opinión de los dueños o empleados de refaccionarias sobre las autopartes chinas y la forma en que impactan el mercado de repuesto en México se obtuvo por 
encuesta. Específicamente nos interesó conocer los problemas que enfrentan y entender la oferta de autopartes chinas. Con base en la información obtenida a través de fuentes secundarias y las entrevistas a expertos se elaboró un cuestionario, que incluyó nueve preguntas abiertas relacionadas con los objetivos específicos y que fue aplicado vía telefónica. La población estuvo compuesta por 304 empresas que se encuentran inscritas en el directorio de la Asociación Nacional de Representantes Importadores y Distribuidores de Refacciones y Accesorios para Automóviles, A. C. (ARIDra) que se ubican en el Distrito Federal. Se tomó una muestra de 56 empresas que fueron seleccionadas de forma aleatoria. La encuesta se aplicó en dos ocasiones; la primera en 2009 y la segunda en septiembre de 2011; en la segunda ocasión no se encontraron 18 refaccionarias de las que se habían encuestado inicialmente y se sustituyeron por otras seleccionadas de igual forma.

El cambio de percepción que arrojó la encuesta se puede resumir en lo siguiente: hay un aumento en la venta de autopartes chinas de 10 puntos porcentuales, disminuyó el número de personas que piensa que son de bajo precio y baja calidad. Apareció un concepto de "partes importadas de marca" refiriéndose a que las multinacionales importan sus autopartes de otros países en donde operan y éstas tienen buena calidad.

Con los datos obtenidos se observa que en 2009 únicamente $54 \%$ de las empresas vendían autopartes chinas mientras que en 2011 el número aumentó a 64.2\%. Las partes de motor y eléctricas fueron las más vendidas en ambas ocasiones: suspensiones, accesorios, tomas de agua, salpicaderas, filtros, cofres, rótulas, reguladores, baleros y crucetas fueron mencionados.

Los entrevistados consideraban que las autopartes chinas eran de baja calidad (78\%) y bajo precio comparadas con las mexicanas, sin embargo en 2011 únicamente $65.6 \%$ contestaron que son de baja calidad. ${ }^{8}$ Esto quiere decir que ha mejorado un poco la opinión que se tiene de las autopartes chinas. Además los entrevistados respondieron que las autopartes de marca como Bosch que vienen de China son buenas y tienen garantía como las hechas en México por el mismo fabricante (Cuadro 5).

En 2009 los encuestados respondieron que las ventas aumentaron 30\%, pero $22 \%$ señaló que el incremento en el número de marcas los perjudicó porque había una gran diversidad y no tenían refacciones para todos los modelos que se iban incorporando. En 2011 encontramos menos empresas que consideran que

$8 \mathrm{Al}$ sumar los tres primeros parámetros del Cuadro 6. 
Lourdes Álvarez y Liliana Cuadros

el crecimiento de marcas y modelos los han perjudicado; de hecho la mayoría considera que las cosas no han cambiado y que las ventas están incrementando $32 \%$ (Cuadro 6.)

Observamos un aumento en la percepción de que las autopartes chinas están desplazando a las mexicanas de 10 puntos porcentuales. En 2009 nos habían indicado que era por el bajo precio, la facilidad de tener acceso a la mercancía china y por ignorancia del comprador sobre las características del producto. En 2011 nos indican que el transporte público es el que más las consume y las compañías de seguros aparecen como un actor importante (Cuadro 7).

Cuadro 5. Qué opinan sus clientes de las características de las autopartes chinas

\begin{tabular}{lcccc} 
& \multicolumn{2}{c}{2009} & \multicolumn{2}{c}{2011} \\
\cline { 2 - 5 } \multicolumn{1}{c}{ Parámetro } & Número & $\%$ & Número & $\%$ \\
\hline Bajo precio. Baja calidad & 17 & $30 \%$ & 17 & 30.3 \\
No sirven & 13 & $23 \%$ & 12 & 21.1 \\
No les convencen & 11 & $20 \%$ & 8 & 14.2 \\
No sé & 7 & $13 \%$ & 4 & \\
Hay de todo. Varía dependiendo la pieza & & $7 \%$ & 8 & 14.1 \\
Las de marca que viene de China salen buenas & & & 7 & 12.5 \\
Son para el apuro & 3 & $5 \%$ & - & - \\
Nunca han tenido queja & 1 & $2 \%$ & - & - \\
Total & 56 & $100 \%$ & 56 & 99.4 \\
\hline
\end{tabular}

Fuente: datos de la encuesta

Cuadro 6. Cómo ha afectado el incremento del parque vehicular a la venta de autopartes

\begin{tabular}{|c|c|c|c|c|}
\hline \multirow[b]{2}{*}{ Parámetro } & \multicolumn{2}{|c|}{2009} & \multicolumn{2}{|c|}{2011} \\
\hline & Número & $\%$ & Número & $\%$ \\
\hline Le ha perjudicado & 12 & 21.4 & 4 & 7.1 \\
\hline Ha incrementado las ventas & 17 & 30.3 & 18 & 32.1 \\
\hline Todo sigue igual & 27 & 48.2 & 30 & 53.5 \\
\hline Hay más competencia & - & - & 4 & 7.1 \\
\hline Total & 56 & 99.9 & 56 & 99.8 \\
\hline
\end{tabular}

Fuente: datos de la encuesta. 
Las importaciones chinas y su impacto en el mercado de autopartes de repuesto mexicano

Cuadro 7. ¿Las autopartes chinas están desplazando a las mexicanas?

\begin{tabular}{|c|c|c|c|c|c|}
\hline & \multicolumn{2}{|c|}{2009} & \multicolumn{2}{|c|}{2011} & \multirow{2}{*}{$\begin{array}{c}\text { Comentarios } \\
\text { Por qué }\end{array}$} \\
\hline & Número & $\%$ & Número & $\%$ & \\
\hline Sí & 27 & 48.2 & 33 & 58.9 & $\begin{array}{l}\text { Bajo precio. } \\
\text { Por ignorancia del comprador } \\
\text { Sobre todo en el transporte público }\end{array}$ \\
\hline No & 19 & 33.9 & 21 & 36.9 & $\begin{array}{l}\text { Por mala calidad } \\
\text { Preferencia del público por lo reportado como hecho en México }\end{array}$ \\
\hline No sé & 3 & 5.3 & 1 & 1.7 & \\
\hline Otro & 7 & 12.5 & 1 & 1.7 & $\begin{array}{l}\text { En algunas cosas como partes eléctricas } \\
\text { Va a depender de las aseguradoras si aceptan las partes }\end{array}$ \\
\hline Total & 56 & 99.9 & 56 & 99.2 & \\
\hline
\end{tabular}

Fuente: datos de la encuesta.

\section{CONCLUSIONES}

El objetivo de este trabajo fue analizar la dinámica de las importaciones de autopartes que llegan de China, el comportamiento ante estos eventos del subsector que surte al mercado de repuestos y el grado de aceptación que tienen estos productos en el mercado mexicano.

Encontramos que el comercio bilateral de autopartes y automotriz se ha incrementado pero la balanza comercial es deficitaria a pesar de que México triplicó sus exportaciones automotrices a China en el último año. En la última década las importaciones de autopartes que hicimos de China fueron 2.6 veces más que las exportaciones; y las importaciones de autopartes que hace China de México no representan ni siquiera el $1 \%$ de su total, lo que nos deja ver oportunidades perdidas en este renglón.

Las importaciones de autopartes chinas se han traducido en estrategias de proveeduría que han implantado las empresas para bajar costos de fabricación, abrir nuevas líneas y evitar la escasez o desabasto de productos.

En los últimos dos años el distribuidor minorista ha mejorado su percepción sobre la calidad de autopartes chinas, las vende más y considera que las autopartes de marca fabricadas por las multinacionales en China son tan buenas como las hechas por estas empresas en México.

Respecto al funcionamiento del mercado de repuesto hemos identificado cinco puntos importantes: la fragmentación, el crecimiento, la especialización, la regulación y la corrupción.

El sector está fragmentado, ninguna empresa tiene una gran participación en el mercado, ni puede influir profundamente en los resultados de todas las 
Lourdes Álvarez y Liliana Cuadros

demás. El sector tiene barreras débiles contra la entrada de nuevos jugadores, hay altos costos de inventarios y fluctuaciones imprevisibles de las ventas.

Considerando el crecimiento de la flota vehicular y su antigüedad, el gasto en reparaciones de vehículos automotores seguirá aumentando y las ventas se incrementarán especialmente en autopartes electrónicas.

La especialización se da cada vez más en el mercado de repuesto ya que el parque vehicular se ha incrementado y el número de marcas y modelos también. No existe una infraestructura adecuada que pueda manejar esta diversidad. Hacen falta sistemas de cómputo adecuados y capacitación para que tanto los distribuidores, las refaccionarias y los talleres automotrices puedan coordinarse y dar un rápido servicio al cliente. Esto es muy importante porque el manejo de inventarios es un factor de éxito para las empresas. Además, si este sistema estuviera bien estructurado se tendría un mayor control para las acciones de contrabando y piratería.

Es necesario que se retome la creación de normas para el sector automotriz y de autopartes y que se obligue a los importadores a que los productos que se introducen al país las cumplan. La piratería es un problema que aqueja al subsector y existen acciones aisladas y poco efectivas por parte del gobierno y las asociaciones que no se han visto reflejadas en los resultados de la industria. Este problema necesita de la unidad y cabildeo de las empresas del sector pero existen muchos intereses encontrados. Algunas empresas importan componentes y encuentran más fácil hacerlo sin tener que cumplir con normas de calidad. En dos años no se ha impulsado ninguna iniciativa para regular mejor esta situación.

En general se puede decir que el gran cambio realizado en estos dos últimos años en el mercado de repuestos automotrices es la percepción que se tiene de las autopartes chinas. Para un gran número de actores se han vuelto una oportunidad, ya que los ayudan a bajar costos de fabricación, a abastecer al mercado, que en ocasiones tiene problemas de desabasto, y a competir con nuevas líneas a precios más bajos. Las autopartes chinas se están integrando al mercado mexicano y cada vez tienen mayor aceptación.

\section{BIBLIOGRAFÍA}

Álvarez Medina, Lourdes, "La industria automotriz china: posibilidades de competir con la industria automotriz en México", en coord. Enrique Dussel y Yolanda Trápaga, China y México: implicaciones de una nueva relación, Ed. Nuestro Tiempo, La Jornada Ediciones, 2007. 
"Comportamiento exportador de la industria automotriz de México y China en el mercado de los Estados Unidos", ponencia presentada en el X Foro de Investigación, Congreso Internacional de Contaduría, Administración e Informática, FCA-UNAM, México, 2005.

y Sepúlveda, Elizabeth, "Reformas económicas, inversión extranjera directa y cambios en la estructura de la industria automotriz china (19802004)", en Contaduría y Administración, núm. 218, México, FCA-UnAM, enero-marzo de 2006, pp. 87-113.

, "La industria automotriz china: competencia y cooperación", Revista Logística y Comercio Intencional, núm. 36, México, abril-mayo, 2006, pp. 16-17.

, "La industria automotriz china: internacionalización y competencia con la industria automotriz en México", presentada en XII Foro de Investigación, Congreso Internacional de Contaduría, Administración e Informática, FCAunam, México, 2007.

Asociación Mexicana de la Industria Automotriz (Amia), Boletín de prensa, diciembre 2008, diciembre 2009, diciembre 2010 y junio, 2011.

Calderón, Jesús, "El mercado de repuesto en México", ponencia presentada en la Reunión de evaluación del mercado de repuesto, Industria Nacional de Autopartes, 19 de enero, México, 2011.

Cometrade map, http://comtrade.un.org/db/ce/ceDefault.aspx, consultado en septiembre de 2011.

Cuadros, Liliana, Competencia México-China en el mercado automotriz: el caso del mercado de repuesto, tesis para obtener el grado de maestra en administración, FCA-UNAM, enero de 2009.

Dussel, Peters, E., "El caso de las estadísticas comerciales entre China y México: para empezar a sobrellevar el desconocimiento bilateral", en Economía informa, núm. 335, Facultad de Economía-unam, México, julio-agosto, 2005, pp. 50-61.

(a), "The Mexican Case", en Jenkins Rise and Dussel Peters (coord.), China and Latin America: Economic Relations in the Twenty_First Century, Deutsches Institut fur Entwicklungspolitik, cechimex-unam, México, 2010, pp. 280-395.

(b), "La cadena autopartes automotriz en México y en China: ipotencial de cooperación?", en coord. Dussel Peters y Yolanda Trápaga, Hacia un diálogo entre México y China, Senado de la República, Comisión de Relaciones Exteriores, México, 2010, p. 272.

Feenstra, Robert y Hiau Looi Kee, "Export Variety: a Comparison of China and Mexico", http://giannini.ucop.edu/Feenstra.pdf, 2004, consultado 3 de noviembre, 2010. 
Lourdes Álvarez y Liliana Cuadros

Fourin, "Monthly Statistics Overview", www.fourin.com, febrero, 2, 2005.

Freyssenet, Michele, The Second Automobile Revolution: Trajectories of the World Carmakers in the 21st Century, Beginnings of a Second Automobile Revolution: Firms Strategies and Public Policy, Palgrave Macmillan, Great Britain, 2009, $468 \mathrm{p}$.

Industria Nacional de Autopartes, Noti-INA, dic., 2008, 2009 y 2011 http:// www.ina.org.mx/

INEGI, Vehículos de motor registrados en circulación, enero, México, 2011.

INEGI, Censos Económicos 2009, http//www.inegi.gob.mx

Martínez, Ignacio, "Hacia un nuevo mecanismo que regule la relación comercial entre México y China”, en coord. Dussel Peters y Yolanda Trápaga, Hacia un dialogo entre México y China, México, 2010.

Martínez, Lorenza, "La era de la productividad. Cómo transformar la economía desde sus cimientos", consultado 12 febrero de 2011.

Morales, Carlos, "El comercio entre China y México: una colosal triangulación", en Comercio Exterior, Banco de Comercio Exterior, diciembre 2008, pp. 885-894.

, "La relación comercial México-China en los últimos 25 años", en coord. Dussel Peters y Yolanda Trápaga, Hacia un diálogo entre México y China, México, 2010.

OICA, Organisation Internationale des Constructeurs d'Automobiles, estadisticas. http://oica.net/category/production-statistics/ consultada en varios meses de 2010 .

Research Departament of Industrial Economy from China, "Anual Report on Automotive Industry in China 2010", documento presentado en la reunión A Dialogue in the Autoparts-Automobile Chain Between Mexico and China, 19 de agosto, Unidad de Seminarios Dr. Ignacio Chávez, Vivero Alto, unam, México, 2010, 246 p.

Rhys Jenkins y Enrique Dussel, "The Impact of China on the Latin American and the Caribbean", DFID China Office (AG44I9), abril, 2006, pp. 1-40, http:/dussel peters

Ríos, Agustín, "The Automotive Parts Industry in Mexico", ponencia presentada en The Mexico Auto Industry Conference, Mexico Now Seminar, San Luis Potosí, México, 2 diciembre, 2008.

Rosales, Osvaldo, "Relaciones estratégicas entre China y América Latina: América del Sur y México-Centroamérica”, Dussel, Peters (coord.), Oportunidades en la relación económica y comercial entre China y México, CEPAL, Cámara de Senadores, Secretaría de Relaciones Exteriores, CECHIMEX-unam, México, 2007, pp. 21-44. 
Secretaría de Economía, estadísticas internacionales, http.//www. Economía. gob, México septiembre de 2011.

Villalobos, Ángel, "La relación comercial China-México", en Dussel, Peters (coord.), Oportunidades en la relación económica y comercial entre China y México, Cepal, Cámara de Senadores, Secretaría de Relaciones Exteriores, CeChimeX- Unam, México, 2007, pp.113-124. 